\title{
NOVAS CONFIGURAÇÕES TERRITORIAIS DECORRENTES DA ACUMULAÇÃO DE CAPITAL NO AGRONEGÓCIO DE MATO GROSSO: ANÁLISE DO MUNICÍPIO DE SORRISO
}

\author{
Eduardo von Dentz 1 \\ Fernando Rodrigo Farias ${ }^{2}$
}

Resumo: O estado de Mato Grosso possui a soja como a principal atividade do setor agropecuário. Enquanto na safra 1997/98 o lucro médio atingido pelos produtores por saca de soja em Mato Grosso foi de $R \$ 2,39$, na safra 2015/16 o lucro aumentou para $R \$ 31,30$ por saca. Esse processo de ampliação da taxa de lucro tornou-se um importante fator que vem transformando a dinâmica econômica dos investimentos tanto endógenos quanto exógenos. O objetivo deste artigo é desvendar a capacidade de acumulação de capital do agronegócio de Mato Grosso e as configurações territoriais decorrentes dessa acumulação. Para alcançar o objetivo, utilizaram-se de quatro passos metodológicos: (1) levantamento de dados e levantamento bibliográfico; (2) trabalhos de campo e visitas técnicas; (3) organização e tratamento dos dados e informações coletadas; e (4) análise dos dados. Um dos principais resultados encontrados mostra que o capital acumulado no agronegócio da soja de Mato Grosso promove transformações territoriais tanto no próprio agronegócio quanto nas cidades.

Palavras-chave: Acumulação de capital. Agronegócio. Mato Grosso. Transformações territoriais.

\section{NEW TERRITORY CONFIGURATIONS DUE TO CAPITAL ACCUMULATION IN THE AGRIBUSINESS OF THE MATO GROSSO: ANALYSIS OF THE MUNICIPALITY OF SORRISO}

\begin{abstract}
The Mato Grosso state has soy as the main activity in agricultural sector. While in the 1997/98 harvest the average profit reached by producers per sack of soybeans in Mato Grosso was $\mathrm{R} \$ 2,39$, in the $2015 / 16$, harvest this profit increased to $\mathrm{R} \$ 31,30$ per sack. This process of increasing the rate of profit has become an important factor that has been transforming the economic dynamics of both endogenous and exogenous investments. The objective this article is to unravel the capacity of capital accumulation of agribusiness in Mato Grosso and the territorial configurations resulting from this accumulation. To achieve the objective, used four methodological steps: 1) data collection and bibliographic survey, 2) fieldwork and technical visits, 3) organization and treatment of data and information collected and 4) data analysis. One of the principally results found was that the capital accumulated in agribusiness of Mato Grosso promote territorial changes both in agribusiness itself in the cities.
\end{abstract}

\footnotetext{
1 Universidade Federal de Santa Catarina, Departamento de Geociências, Florianópolis, Brasil, eduardovondentz@hotmail.com, https://orcid.org/0000-0002-0280-1149

2 Universidade Federal de Mato Grosso do Sul, Departamento de Geografia, Aquidauana, Brasil, fernando.rodrigo@ufms.br, http://orcid.org/0000-0001-6426-8987
} 
Keywords: Capital accumulation. Agribusiness. Mato Grosso. Territory's transformations.

\section{NUEVAS CONFIGURACIONES TERRITORIALES DECORIENTES DE LA ACUMUULACIÓN DE CAPITAL EN EL AGRONEGOCIO DE MATO GROSSO: ANALISIS DE LA MUNICIPALIDAD DE SORRISO}

Resumen: El estado de Mato Grosso tiene en la soya como la principal actividad del sector agropecuario. Mientras en la cosecha 1997/98 el lucro promedio atingido por los productores y por saco en Mato Grosso fue de $R \$ 2,39$, en la cosecha 2015/16 ese lucro aumentó para $\mathrm{R} \$ 31,30$ por saco. Ese proceso de ampliación de la taja de lucro se tornó un importante factor que viene transformando la dinámica económica de los investimentos tanto endógenos cuanto exógenos. El objetivo de este artículo es desvendar la capacidad de acumulación de capital del agronegocio de Mato Grosso y las configuraciones territoriales consecuentes de esta acumulación. Para alcanzar el objetivo, se utilizó de cuatro pasos metodológicos: 1) levantamiento de dados y levantamiento bibliográfico, 2) trabajos de campo y visitas técnicas, 3) organización y tratamiento de los dados y informaciones colectadas e 4) análisis de los dados. Uno de los principales resultados encontrados fue que el capital acumulado en el agronegocio de Mato Grosso promueve transformaciones territoriales tanto en el proprio agronegocio cuanto en las ciudades.

Palabras clave: Acumulación de capital. Agronegocio. Mato Grosso. Transformaciones territoriales.

\section{Introdução}

Nas últimas décadas, principalmente após 2003, o Brasil passou por profundas transformações econômicas, sociais e regionais. Essas transformações podem ser constatadas ao se verificar o volume expressivo de empregos gerados, 0 aumento real do salário mínimo dos trabalhadores e a expansão do consumo em todas as camadas de renda da população brasileira. Esses aspectos, conforme apontam Bielschowsky (2013) e Espíndola (2016), são decorrentes de um ciclo de crescimento da economia nacional entre 2003 e 2014. Somente entre 2003 e 2011 o Brasil acumulou aumento do produto interno bruto (PIB) de 42,1\%, tendo a taxa de desemprego saído de 11,6\%, em 2002, para 5,5\%, em 2012, considerando a população ocupada (IBGE, 2016).

$\mathrm{Na}$ engrenagem da economia nacional, o estado de Mato Grosso (MT) também passou por importantes transformações sociais e econômicas. Segundo o Instituto Mato-grossense de Economia Agrícola (IMEA, 2016), o PIB de MT passou de $\mathrm{R} \$ 19,1$ bilhões, em 2001, para 126,8 bilhões, em 2016. Já o PIB do agronegócio de MT passou de $R \$ 21,4$ bilhões, em 2010, para $R \$ 56,3$ bilhões, em 2016. 
Ademais, em 2002 o estado de MT representava 1,3\% do PIB brasileiro, tendo alcançado $2 \%$ em 2016. Além disso, diferentemente do que ocorre em outros estados, em MT o PIB do agronegócio é bastante representativo, tendo alcançado, em 2016, 22,4\% de participação no PIB total do estado.

O estado de MT tornou-se, do início da década de 2000 para cá, o maior produtor brasileiro de soja, algodão, milho, girassol e carne bovina, possuindo projeção de se tornar o maior produtor em outros segmentos, como no trigo, por exemplo (IMEA, 2016). De acordo com levantamento da Companhia Nacional de Abastecimento (CONAB, 2018), na safra 2017/2018, o estado do MT plantou 9,519 milhões de hectares de soja, com uma produção de 31,887 milhões de toneladas e com uma produtividade de $3.350 \mathrm{~kg} / \mathrm{ha}$. O estado de MT foi responsável por 27,25\% da produção nacional de soja na safra em que os dados foram mencionados, confirmando-se como maior produtor nacional do grão.

As alterações de ordem econômico-social em MT, estritamente ligadas ao agronegócio, foram objeto de estudo envolvendo a temática em foco em diversos estudos, dentre eles: Frederico (2008), Von Dentz (2018), Bernardes (2015). Esses autores destacam a expansão da fronteira agrícola no estado de MT, o crescimento econômico ocorrido, a migração de pessoas para o referido estado em busca de empregos, dentre outros. Em que pese a importância das pesquisas já realizadas, nenhuma delas aponta para as configurações territoriais promovidas pela acumulação de capital no agronegócio do estado. Dessa maneira, este artigo tem por objetivo desvendar a capacidade de acumulação de capital do agronegócio de Mato Grosso e as configurações territoriais decorrentes dessa acumulação.

Para alcançar o objetivo proposto, seguiram-se quatro passos metodológicos: (1) levantamento de dados e levantamento bibliográfico; (2) trabalhos de campo e visitas técnicas; (3) organização e tratamento dos dados e informações coletadas; (4) análise dos dados. Nesse sentido, dividiu-se o artigo, além desta introdução, em quatro partes principais. Num primeiro momento, aborda-se sobre a ocupação territorial e o desenvolvimento do agronegócio no estado de MT. A segunda parte é a respeito do potencial produtivo e da lucratividade obtida pelos produtores do agronegócio de MT. Na terceira parte expõem-se as novas configurações territoriais decorrentes do capital acumulado no agronegócio de MT. Na quarta e última parte, apresentam-se as considerações finais. 


\section{Ocupação territorial e o desenvolvimento do agronegócio em Mato Grosso}

A bibliografia que versa sobre a ocupação do estado de MT quase sempre o faz abarcando no mesmo contexto a ocupação do Cerrado brasileiro e da grande região Centro-Oeste do Brasil. Desse modo, Frederico (2008) esclarece que a expansão da fronteira agrícola para as áreas de Cerrado permitiu que o estado de MT se tornasse o maior produtor nacional de grãos. No entanto, a história aponta que os caminhos que levavam à exploração do ouro em áreas de Goiás (GO) e na baixada cuiabana, ainda nos séculos XVIII e XIX, deixaram algumas heranças, presentes em uma incipiente rede urbana, que de início pode ser considerada subproduto da atividade mineradora, depois da atividade madeireira, e, na sequência, dos programas de colonização e construção planejada de algumas cidades, sobretudo em fundos de vales, onde o acesso à água era facilitado (VON DENTZ, 2018).

Nesse sentido, a formação geoeconômica de MT está ligada ao avanço das atividades agrícolas, mas também à constituição dispersa de núcleos urbanos. Von Dentz (2018) salienta que tanto as atividades agrícolas quanto a constituição de núcleos urbanos estão ligadas à expansão das redes de transporte e comunicação, que passam a interligar, mesmo que de forma precária no início, a referida região, principalmente ao estado de São Paulo. A relação de MT com o estado de São Paulo data do final do século XVI e início do século XVII, com o advento dos Bandeirantes Paulistas, que abriam caminhos em busca de metais preciosos e outras riquezas. No entanto, o estabelecimento das redes de transporte efetivou-se no século XVIII, quando foi descoberto ouro em MT e GO (FREDERICO, 2008).

No século XVIII, dois caminhos foram abertos e podem ser citados como principais: um por água (fluvial), utilizando-se dos rios Tietê, Paraná e Paraguai, e outro por terra (terrestre), que passava pelo Triângulo Mineiro e GO, até chegar em Cuiabá, atual capital do MT. Dessa forma, a atividade de mineração e, posteriormente, a atividade madeireira estimularam a construção das redes de transporte e interferiram na criação dos primeiros núcleos urbanos, vilas e povoados (DINIZ, 2006). No século XIX, conforme Guimarães e Leme (2002, p. 24), o Cerrado de Mato Grosso passou a ser caracterizado como "uma pequena área de pecuária e de agricultura de subsistência, com pequena articulação com os centros mais desenvolvidos do país e quase nenhuma integração econômica interna". O estado do MT, sobretudo as áreas de Cerrado, posteriormente servidas às atividades 
agropecuárias, eram de características semelhantes às de $\mathrm{GO}$, considerando 0 isolamento em relação às regiões de acesso ao litoral (VON DENTZ, 2018).

O isolamento do Cerrado de MT diminui quando, no estado de SP, foi implantado o complexo cafeeiro, e, consequentemente, a malha ferroviária se expande para o Triângulo Mineiro, GO e MS (que pertencia a MT); aumentando, assim, a influência exercida por SP sobre essas áreas (FREDERICO, 2008). A expansão da malha ferroviária para os estados de GO e MT fez com que essas regiões se integrassem mais com o estado de SP - considerado o centro consumidor e das atividades econômicas do país -, o que fez surgir e se consolidar novas vilas e cidades. Nessa direção, todo o território brasileiro sofreu impactos dessas mudanças (VON DENTZ, 2018).

As políticas de Estado, que prezavam pela ampliação do mercado interno, presidido pela indústria, fizeram aumentar a demanda por produtos alimentícios, o que criou maior interrelação com as regiões agropecuárias. Daí resultaram as políticas de colonização e a chamada "Marcha para o Oeste", ainda na terceira década do século XX. Guimarães e Leme (2002) ressaltam que, associada às transformações internas de GO e MT, nos anos 1930-45, houve uma política deliberada do governo federal de ocupação das fronteiras, de preenchimento dos vazios demográficos, conhecida como Marcha para o Oeste. Tratava-se de uma política de integração do mercado nacional, a partir da qual se percebeu forte comando econômico pelo estado de SP.

Até então, as áreas econômicas eram localizadas e descontínuas; mas a partir dos anos 1930, o modelo implantado para a economia nacional objetivava superar o capitalismo agrário e mercantil, assentado na atividade exportadora, buscando uma nova ordem econômica, presidida pela dinâmica industrial e pelo mercado interno (VON DENTZ, 2018). A política de fortalecimento da indústria fez o projeto da Marcha para o Oeste se consolidar mais rápido, pois com a ocupação do Centro-Oeste (principalmente de MT), novos complexos produtivos, sobretudo ligados à agricultura, surgiram no Cerrado. Assim, Guimarães e Leme (2002) ressaltam que a política de integração nacional visava um modelo econômico nacional mais voltado para o desenvolvimento do mercado interno.

A nova dinâmica econômica passou a dar novos ares à indústria nacional na ótica do abastecimento do mercado interno. Nesse contexto, avançados os anos 1950 e 1960, criava-se um cenário distinto de possibilidades para a ocupação do 
Centro-Oeste do Brasil. Ao passo que as possibilidades de ocupação do CentroOeste surgiam, os agricultores sulistas (oriundos especialmente do Norte e Noroeste do RS, Oeste de SC e Oeste e Sudoeste do PR), que já haviam explorado as áreas do Sul desde o final do século XIX até a segunda metade do século XX, viviam em situação econômica desfavorável ao mantimento das atividades agrícolas no Sul. Questões como endividamento agrícola, baixa fertilidade do solo e pequenas propriedades rurais (de no máximo 30, 40 hectares) fizeram com que os agricultores do Sul olhassem com bons olhos o projeto do governo de ocupação das áreas do Centro-Oeste (VON DENTZ, 2018).

A partir dos anos 1970, pode-se dizer que os primeiros sulistas começaram a migrar para áreas de MT, primeiramente na região Sul do estado (Rondonópolis, Campo Verde, Primavera do Leste), e depois para a região Leste, Centro e Oeste do estado (Querência, Lucas do Rio Verde, Sorriso, Campo Novo do Parecis e outros municípios). Nesse sentido, Fici (2007) ressalta que as áreas produtivas do estado do MT foram incorporadas ao espaço produtivo do Brasil a partir de 1970, por meio dos incentivos governamentais para a agricultura. A expansão da fronteira agrícola no estado de MT está estritamente ligada à distribuição da malha rodoviária, da ferroviária e da hidroviária da região ( $F I C l, 2007)$. A importância das vias de transporte foi aumentando ao passo em que se tornou cada vez mais possível apostar no MT como um estado promissor na atividade agrícola (VON DENTZ, 2018).

Dessa maneira, a arrancada no desenvolvimento do MT está na atividade agrícola, tendo no plantio em larga escala um fator determinante para 0 desenvolvimento de sementes adaptadas geneticamente e de novas tecnologias de preparo do solo. De acordo com Rezende (2002), a partir de 1980 houve redução das pastagens naturais e das áreas cultivadas com arroz, em consequência do aumento das áreas cultivadas com algodão, cana-de-açúcar, soja e milho. Isso ocorreu em virtude da utilização de novas tecnologias que permitiram o cultivo dessas culturas agrícolas no solo do Cerrado, até então visto como pouco fértil. Ademais, o relevo plano dessas terras favoreceu a utilização intensiva de maquinaria nos processos produtivos.

Nesse contexto, a ocupação do Cerrado mato-grossense é resultado de um projeto político e econômico almejado pelo Estado. Com base nos aspectos inerentes ao processo de ocupação do estado de MT aqui postos, o tópico a seguir 
versa sobre o potencial produtivo recente do estado de MT, bem como acerca da capacidade de lucro obtida pelos produtores agrícolas do estado.

\section{O potencial produtivo e a lucratividade obtida pelos produtores do agronegócio de Mato Grosso}

Além da disponibilidade em grande escala de terras planas, o regime de chuvas bem definido (seis meses de chuva - setembro a fevereiro - e seis meses de seca - março a agosto) na maior parte do estado de MT, são fatores físicoclimáticos fundamentais para que a agricultura de grãos pudesse alcançar 0 potencial produtivo atual (Gráfico 1). Ao levar em conta a evolução da produção de grãos no MT, os dados da Conab (2016) e do IMEA (2016), sistematizados no Gráfico 1, apontam que no início da década de 2000, a produção foi de aproximadamente 12 milhões de toneladas, em uma área de aproximadamente 4 milhões de hectares. Esses números atingiram a marca aproximada de 52 milhões de toneladas em uma área de 13 milhões de hectares na safra 2015/2016. Ou seja, em quinze anos a produção de grãos quase quintuplicou, e a área de produção pouco mais que triplicou no MT (Gráfico 1$)^{3}$.

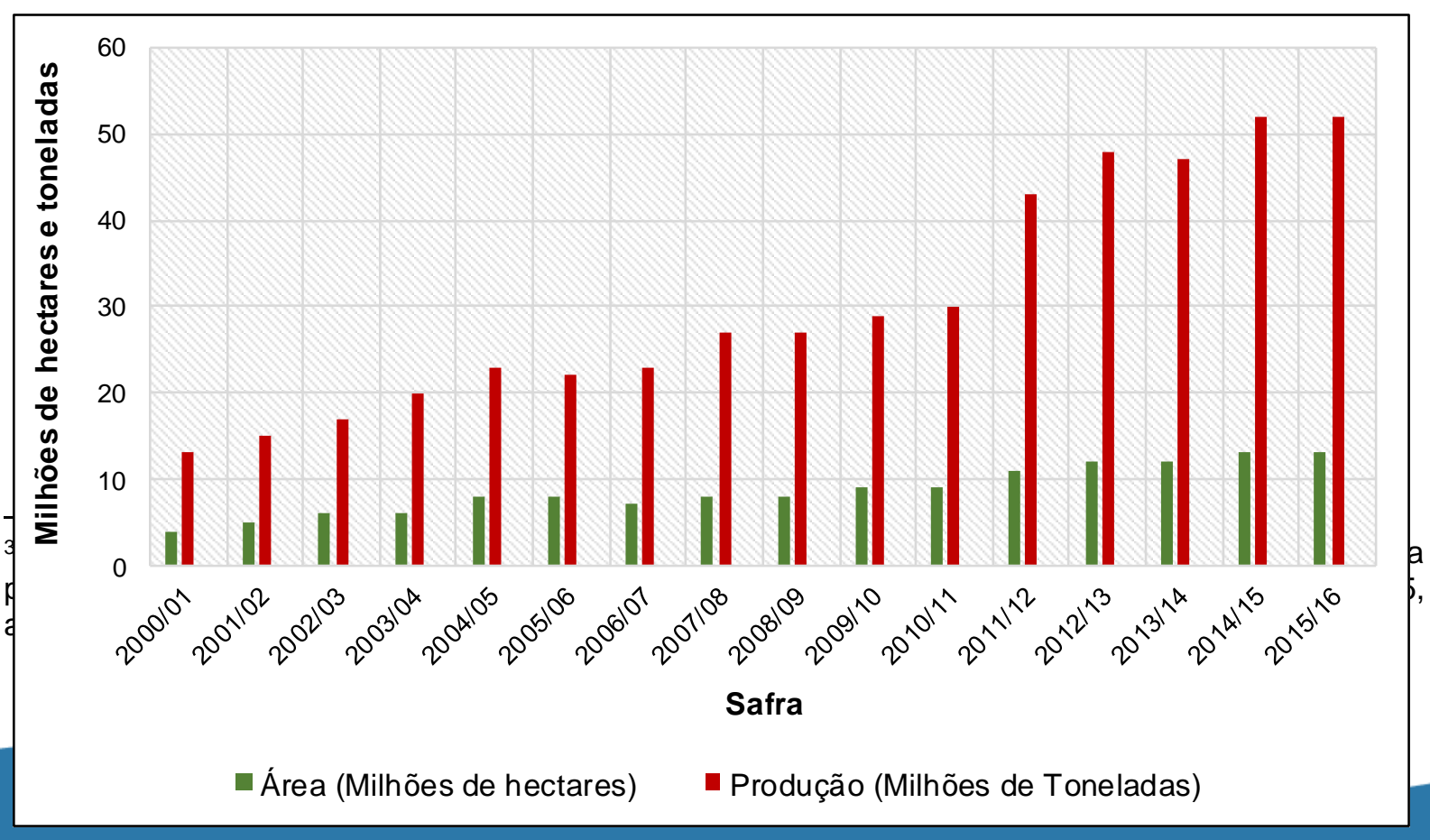


Gráfico 1 - Produção agrícola e área plantada no Mato Grosso (2000/01 - 2015/16) ${ }^{4}$ Fonte: Conab e IMEA, 2016.

Trata-se, como aponta o Gráfico 1, de um crescimento quase ininterrupto da produção de grãos em MT no período de 2000/01 a 2015/16. Nesse contexto, a representatividade da cultura da soja sobre as demais culturas produzidas no estado do MT é bastante superior. Dos 52 milhões de toneladas de grãos que o estado produziu na safra 2015/2016, quase 30 milhões de toneladas foram de soja.

Em termos de área plantada de soja no estado de MT, em 1990 o estado plantou um total de 1,1 milhão de hectares, tendo atingido a marca de 8,9 milhões de hectares de soja plantada em 2014. Em 1990, os municípios que mais plantaram soja no estado foram: Alto Taquari (54 mil ha), Campo Novo do Parecis (200,8 mil ha), Campo Verde (101,8 mil ha), Diamantino (100 mil ha), Itiquira (117,4 mil ha), Lucas do Rio Verde (65,5 mil ha), Nova Mutum (66,7 mil ha), Primavera do Leste (136,7 mil ha), Rondonópolis (69,7 mil ha) e Sorriso (140 mil ha). Em 2014, os municípios que mais plantaram soja no estado de Mato Grosso foram: Brasnorte (211 mil ha), Canarana (213,5 mil ha), Diamantino (311 mil ha), Lucas do Rio Verde (256,4 mil ha), Nova Mutum (400 mil ha), Nova Ubiratã (348,8 mil ha), Primavera do Leste (251,5 mil ha), Querência (305,2 mil ha), Sapezal (385 mil ha) e Sorriso (635 mil ha). Nos Mapas 1 e 2 é possível verificar o avanço ocorrido na área plantada de soja no estado de MT, considerando, respectivamente, os anos de 1990 e 2014.

Mapa 1 - Área plantada de soja no estado de Mato Grosso - 1990

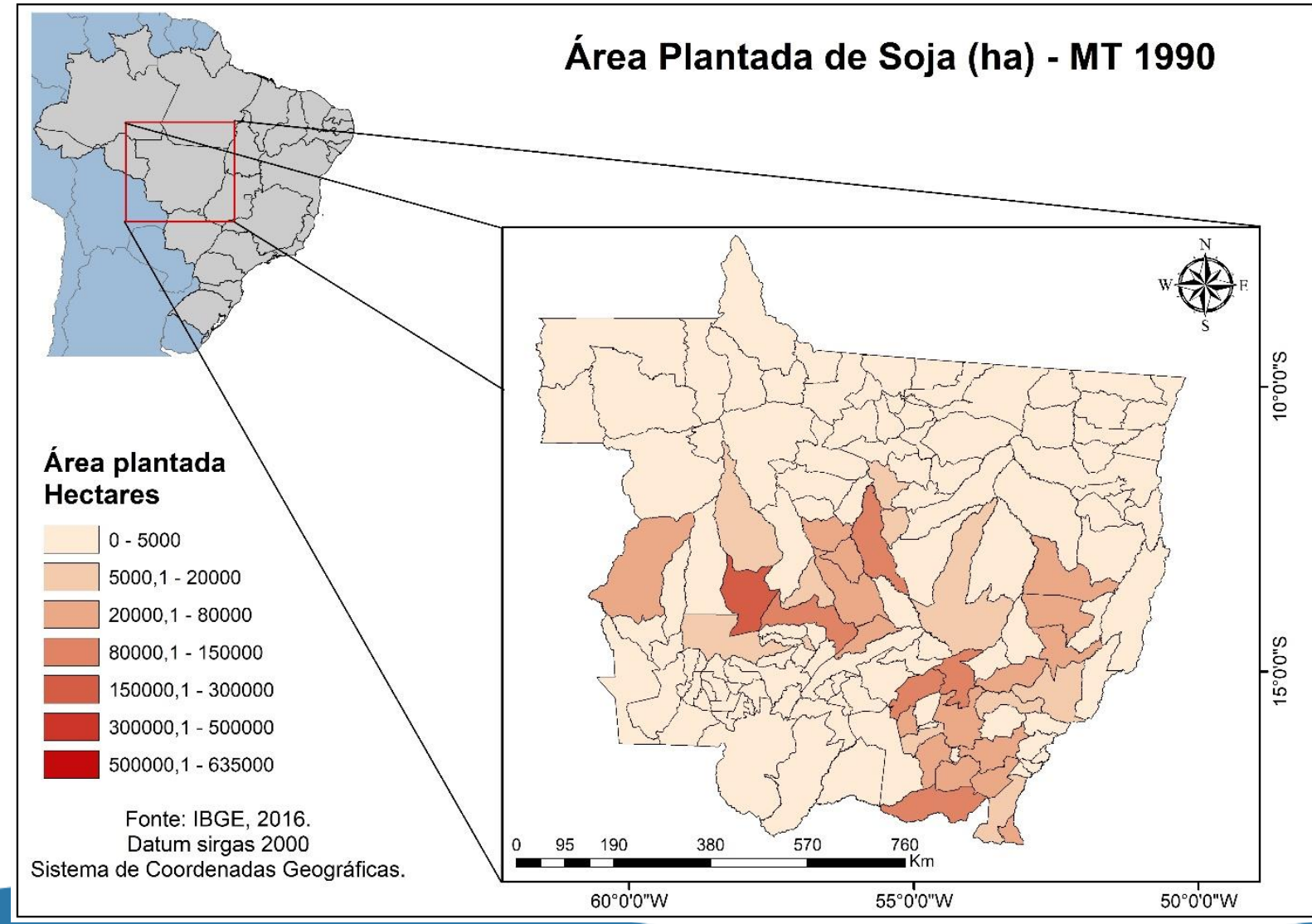


Fonte: Produção Agrícola Municipal (IBGE, 1990).

Mapa 2 - Área plantada de soja no estado de Mato Grosso - 2014

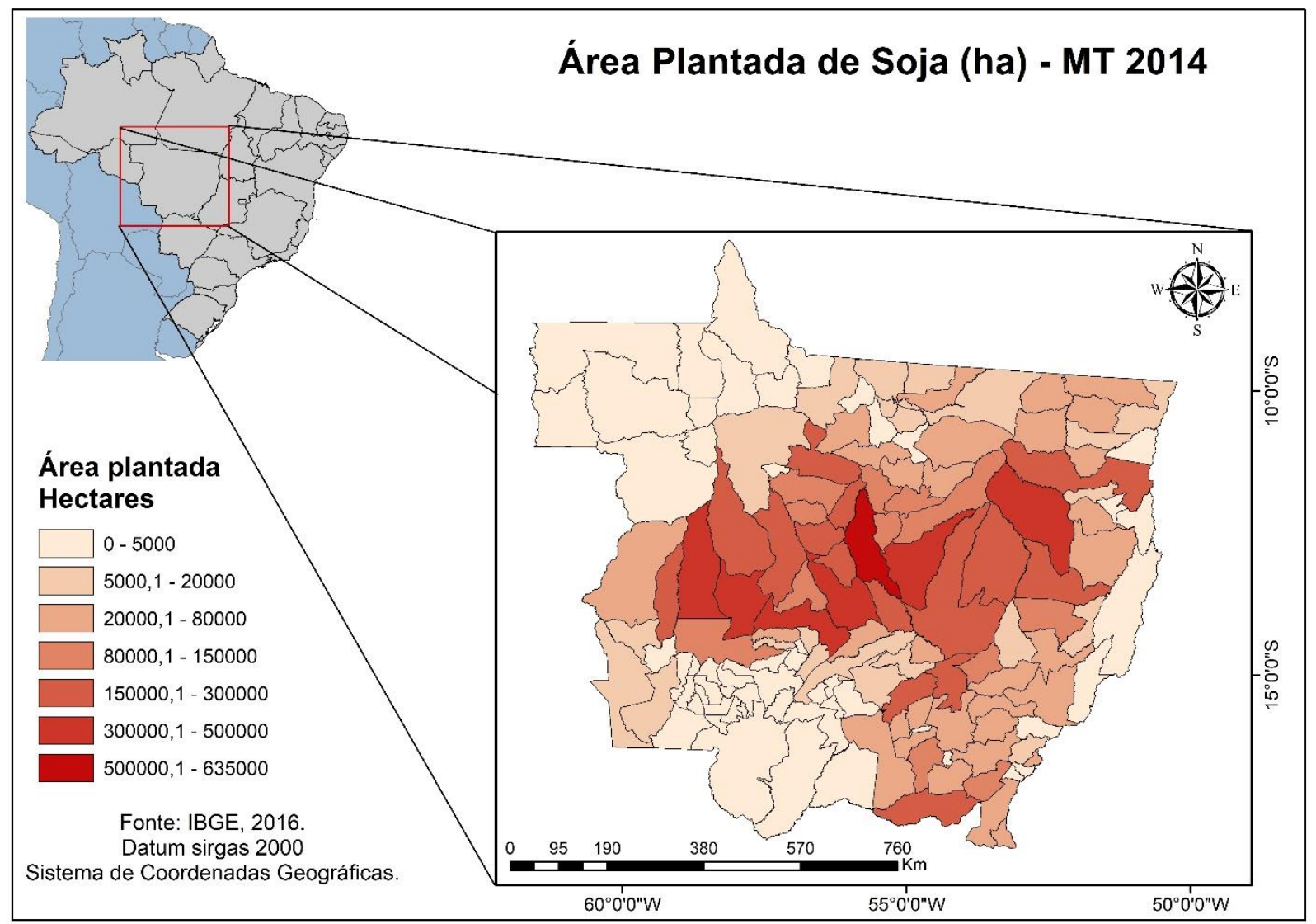

Fonte: Produção Agrícola Municipal (IBGE, 2016).

A comparação entre os Mapas 1 e 2 demonstra que a cultura da soja passou por forte crescimento na extensão de área plantada. Chama a atenção a verificação de que a cultura da soja se espalhou em toda a região central do estado, confirmando-se área onde a cultura é produzida em maior quantidade. Ademais, grande parte das regiões Leste e Sul do estado, exceto nos municípios vizinhos de Poconé, nos quais predomina o bioma Pantanal, que torna impossível o cultivo da oleaginosa, também se consolidaram como importantes áreas de plantio da soja. $\mathrm{Na}$ porção Oeste de MT, a soja encontrou a divisa com o estado de Rondônia, ao mesmo tempo em que, na parte Norte do estado, inúmeros municípios que se limitam com o estado do PA tornaram-se importantes produtores da soja, com grandes áreas cultivadas (Mapa 2).

O fato de a soja ser a cultura mais produzida no estado de MT implica dizer que é a cultura que dá aos agricultores maior lucratividade. Nessa linha de raciocínio, as Tabelas 1 e 2 apontam para a descrição dos custos de produção que 
os agricultores de MT possuem com a cultura da soja. Com esse panorama, é possível ter uma estimativa real da lucratividade dos agricultores com esse tipo de cultivo. Para isso, tanto na Tabela 1 quanto na Tabela 2 os cálculos foram realizados tendo em conta uma área de 1.500 hectares $^{5}$.

Como pode ser visto na Tabela 1, na safra 1997/98, o custo de produção de soja por hectare era de $\mathrm{R} \$ 444,61$. Nessa mesma safra, o custo de produção representado por saca de soja foi de $\mathrm{R} \$ 9,54$. Com os custos de produção obtidos, considerando a série histórica de preços por saca de soja da Aprosoja/MT, em 1998 o valor pago pela saca de soja aos agricultores em Sorriso/MT - local do levantamento do custo de produção (Tabelas 1 e 2 ) - era de $R \$ 11,93$. Assim, subtraindo do valor pago por saca nessa safra $(\mathrm{R} \$ 11,93)$ o custo total por saca de soja $(R \$ 9,54)$, os agricultores obtiveram lucro líquido de $R \$ 2,39$ por saca na safra mencionada.

Por outro lado, na safra 1997/98, a produtividade média da soja em Sorriso foi de 46,6 sacas por hectare. Com isso, ao ser multiplicado o lucro por saca pelo número de sacas produzidas por hectare, o agricultor, na referida safra, chegou a um lucro líquido de $\mathrm{R} \$ 111,37$ por hectare. Considerando ainda que a quantidade média de hectares por propriedade rural de Mato Grosso é de 1500 hectares, na safra de 1997/98 o agricultor conseguiu chegar, com a lavoura de soja, a um lucro líquido de aproximadamente $\mathrm{R} \$ 167 \mathrm{mil}^{6}$.

Tabela 1 - Custo de produção do plantio direto de soja em Sorriso/MT - safra 1997/98 Produtividade média por hectare: $2.800 \mathrm{~kg}=46,6$ sacas $^{7}$ DISCRIMINAÇÃO ${ }^{8}$

1 - Operação com aviões (R\$)

2 - Operação com máquinas 3 - Mão de obra temporária CUSTO POR ha 28,50 27,81 CUSTO/SACA $60 \mathrm{Kg}$ (R\$) 1,78 0,61 0,60 0,04

\footnotetext{
5 Tamanho médio das propriedades rurais do Mato Grosso de acordo com o INCRA.

${ }^{6}$ Esses cálculos foram feitos sobre as médias gerais e tendo em conta os custos de produção levantados pela Conab e por informações coletadas nos trabalhos de campo realizados em outubro de 2016 e setembro de 2017 com produtores de soja de Sorriso/MT.

${ }^{7}$ É preciso considerar, ainda, que os dados apresentados nas Tabelas 1 e 2 foram calculados com base nas médias de produtividade. Assim, considera-se que a produtividade pode alcançar valores maiores que a média apresentada, ou menores, dependendo da região e da qualidade/quantidade de investimentos feitos pelos agricultores. Além disso, a produtividade também pode variar dependendo do valor da saca de soja do ano/safra, pois isso influencia os agricultores a investirem mais nas lavouras, ou menos. À parte disso, estiagens e outras intempéries climáticas podem influenciar na produtividade da soja (essa análise também é válida para outras culturas agrícolas, como o milho, por exemplo).

${ }^{8}$ De acordo com preços de maio de 1997, época em que os agricultores se organizam para obter os insumos necessários para o plantio, que se inicia em agosto/setembro, dependendo do início do período de chuva.
} 


\begin{tabular}{|c|c|c|}
\hline 4 - Mão de obra fixa & 7,20 & 0,15 \\
\hline 5 - Sementes & 38,50 & 0,83 \\
\hline 6 - Fertilizantes & 136,50 & 2,93 \\
\hline 7 - Defensivos & 97,44 & 2,09 \\
\hline $\begin{array}{l}\text { TOTAL DAS DESPESAS DE CUSTEIO DA } \\
\text { LAVOURA (A) }\end{array}$ & 337,73 & 7,25 \\
\hline 8 - Recepção, limpeza e secagem & 16,32 & 0,35 \\
\hline 9 - Transporte externo & 9,80 & 0,21 \\
\hline TOTAL DAS DESPESAS PÓS-COLHEITA (B) & 26,12 & 0,56 \\
\hline $10-$ Juros & 23,08 & 0,49 \\
\hline 11 - PROAGRO & 13,17 & 0,28 \\
\hline 12 - Assistência técnica & 6,75 & 0,14 \\
\hline TOTAL DAS DESPESAS FINANCEIRAS (C) & 43,00 & 0,92 \\
\hline 13 - Depreciação de benfeitorias/instalações & 2,26 & 0,05 \\
\hline 14 - Depreciação de implementos & 5,53 & 0,12 \\
\hline 15 - Depreciação de máquinas & 16,46 & 0,35 \\
\hline TOTAL DE DEPRECIAÇṌES (D) & 24,25 & 0,52 \\
\hline 16 - Manutenção periódica de máquinas & 7,89 & 0,17 \\
\hline 17 - Encargos sociais & 4,25 & 0,09 \\
\hline 18 - Seguro do capital fixo & 1,37 & 0,03 \\
\hline TOTAL DE CUSTOS FIXOS (E) & 13,51 & 0,29 \\
\hline CUSTO TOTAL (A+B+C+D+E) & 444,61 & 9,54 \\
\hline
\end{tabular}

Fonte: Conab, 2016 e trabalhos de campo. Organizado pelos autores.

Para além do exposto, a disparidade fundiária no estado de MT é grande (muitos agricultores plantam menos que 1.500 ha e outros possuem fazendas muito maiores que 1.500 ha $^{9}$ ). Da mesma forma, também é preciso considerar que os custos de produção e o valor da saca de soja variam de região para região e de período para período. Essas questões devem ser levadas em conta, no entanto, não tiram a base de análise do custo de produção e possível obtenção de lucro dos agricultores apresentadas nas Tabelas 1 e 2 . A Tabela 2 mostra um panorama dos custos de produção da soja na safra 2015/16, considerando a mesma localidade da Tabela 1.

Tabela 2 - Custo de produção do plantio direto de soja em Sorriso-MT - safra 2015/16 Produtividade $=3.180 \mathrm{Kg} / \mathrm{ha}=53 \mathrm{sacas} / \mathrm{ha}$

\begin{tabular}{|l|c|c|}
\hline DISCRIMINAÇÃO $^{10}$ & $\begin{array}{c}\text { CUSTO POR ha } \\
\text { (R\$) }\end{array}$ & $\begin{array}{c}\text { CUSTO/SACA 60Kg } \\
\text { (R\$) }\end{array}$ \\
\hline 1 - Operação com máquinas: & & \\
\hline 1.1 - Tratores e colheitadeiras & 105,16 & 1,99 \\
\hline
\end{tabular}

\footnotetext{
${ }^{9}$ A título de exemplo, o grupo Maggi planta em torno de 200 mil ha em várias áreas espalhadas na região Oeste e central de MT, o que deixa implícita a diferenciação de lucro com a lavoura de soja que ocorre a partir da diferenciação do tamanho das propriedades rurais (informação coletada em trabalho de campo). Ademais, há grande quantidade de produtores de soja com áreas plantadas acima de 10 mil ha. No município de Sorriso, a fazenda do produtor na qual se realizou trabalho de campo conta com uma área plantada de $18 \mathrm{mil} \mathrm{ha}$ de soja.

${ }^{10}$ De acordo com preços de maio de 2016.
} 


\begin{tabular}{|l|c|c|}
\hline 2 - Administrador & 6,52 & 0,12 \\
\hline 3 - Sementes & 168,30 & 3,18 \\
\hline 4 - Fertilizantes & 729,89 & 13,78 \\
\hline 5 - Agrotóxicos & 657,52 & 12,41 \\
\hline 6 - Análise de solo & 1,60 & 0,03 \\
\hline $\begin{array}{l}\text { TOTAL DAS DESPESAS DE CUSTEIO DA } \\
\text { LAVOURA (A) }\end{array}$ & $\mathbf{1 . 6 6 8 , 9 9}$ & $\mathbf{3 1 , 5 1}$ \\
\hline 7 - Transporte externo & 73,14 & 1,38 \\
\hline 8 - Despesas: & & \\
\hline 8.1 - Despesas administrativas & 50,07 & 0,94 \\
\hline 8.2 - Despesas de armazenagem & 69,97 & 1,32 \\
\hline 9 - Assistência técnica & 33,38 & 0,63 \\
\hline 10 - CESSR ${ }^{11}$ & 60,00 & 1,13 \\
\hline TOTAL DAS OUTRAS DESPESAS (B) & $\mathbf{2 8 6 , 5 6}$ & $\mathbf{5 , 4 0}$ \\
\hline 11 - Juros do financiamento & 52,44 & 0,99 \\
\hline TOTAL DAS DESPESAS FINANCEIRAS (C) & $\mathbf{5 2 , 4 4}$ & $\mathbf{0 , 9 9}$ \\
\hline CUSTO VARIÁVEL (A+B+C=D) & $\mathbf{2 . 0 0 7 , 9 9}$ & $\mathbf{3 7 , 9 0}$ \\
\hline 12 - Depreciação de benfeitorias/instalações & 43,55 & 0,82 \\
\hline 13 - Depreciação de implementos & 41,88 & 0,79 \\
\hline 14 - Depreciação de máquinas & 55,44 & 1,05 \\
\hline TOTAL DE DEPRECIAÇÕES (E) & $\mathbf{1 4 0 , 8 7}$ & $\mathbf{2 , 6 6}$ \\
\hline 15 - Manutenção periódica (benfeitorias e & 3,99 & 0,08 \\
instalações) & & \\
\hline 16 - Seguro do capital fixo & 5,76 & 0,11 \\
\hline TOTAL DE OUTROS CUSTOS FIXOS (F) & $\mathbf{9 , 7 5}$ & $\mathbf{0 , 1 9}$ \\
\hline CUSTO FIXO (E+F=G) & $\mathbf{1 5 0 , 6 2}$ & $\mathbf{2 , 8 5}$ \\
\hline CUSTO OPERACIONAL (D+G=H) & $\mathbf{2 . 1 5 8 , 6 1}$ & $\mathbf{4 0 , 7 5}$ \\
\hline 17 - Remuneração sobre o capital fixo & 54,65 & $\mathbf{1 , 0 3}$ \\
\hline 18 - Terra própria & $\mathbf{3 5 , 6 0}$ & $\mathbf{1 , 7 0}$ \\
\hline TOTAL DE RENDA DE FATORES (I) & $\mathbf{9 0 , 2 5}$ & $\mathbf{4 2 , 4 5}$ \\
\hline CUSTO TOTAL (H+I=J) & $\mathbf{2 . 2 4 8 , 8 6}$ & \\
\hline Font Conb, & \\
\hline
\end{tabular}

Fonte: Conab, 2016 e trabalhos de campo. Organizado pelos autores.

De acordo com os dados da Tabela 2, os custos de produção por hectare aumentaram significativamente da safra 1997/98 (R\$444,61 - Tabela 1) para a safra 2015/16 (2.248,86 - Tabela 2). De uma safra para outra, o custo de produção quintuplicou. Esse aumento se deve à inflação dos preços puxada pela subida do dólar. Com o aumento do dólar, grande parte dos fertilizantes agroquímicos, agrotóxicos e sementes igualmente sobem o preço, pois são setores comandados por oligopólios internacionais, que têm por base o dólar para cotação de preços. Além disso, a maior parte dos insumos agrícolas consumidos no Brasil são importados, o que contribui, sobretudo em período em que o dólar está alto, para o encarecimento do custo de produção. No entanto, o preço da soja também

\footnotetext{
${ }^{11}$ Contribuição Especial para a Seguridade Social Rural.
} 
aumentou significativamente, tendo sido comercializada em 2016 por $R \$ 73,75^{12}$ a saca de $60 \mathrm{~kg}$.

O custo de produção da soja (Tabela 2), na safra 2015/16, por hectare, foi de $\mathrm{R} \$ 2.248,86$. Na mesma safra, o custo de produção da lavoura de soja por saca foi de $R \$ 42,45$. Com esses custos de produção, considerando o preço da saca de soja nos registros e cotações da Aprosoja-MT, em 2016, o valor pago por saca aos agricultores de Sorriso ficou em $\mathrm{R} \$ 73,75$. Com os custos de produção obtidos e o valor da saca pago aos produtores, subtrai-se do valor pago aos produtores $(R \$ 73,75)$ o custo de produção por saca $(R \$ 42,45)$. Desse cálculo, estima-se que os agricultores, na safra 2015/16, chegaram a um lucro líquido de $R \$ 31,30$ por saca. Com produtividade média de 53 sacas por hectare na safra 2015/16, multiplicado pelo lucro líquido por saca $(\mathrm{R} \$ 31,30)$, os agricultores chegaram a um lucro líquido de $\mathrm{R} \$ 1.568,90$ por hectare de soja em Sorriso. Considerando ainda que a quantidade média de hectares por propriedade rural do MT é de 1.500 hectares, na safra 2015/16 os agricultores chegaram, com a lavoura de soja, a um lucro líquido de $\mathrm{R} \$ 2.488 .350,00$.

Com esses cálculos, a primeira impressão é de que a lucratividade dos agricultores de MT, tendo por base os custos de produção do município de Sorriso, aumentou significativamente, saindo de $R \$ 167.000,00$ na safra de 1997/98 (Tabela 1) para $R \$ 2.488 .350,00$ na safra de $2015 / 16$ (Tabela 2). Esse salto representa um aumento aparente de aproximadamente quinze vezes o montante lucrado por um agricultor no período. Contudo, da safra 1997/98 para a safra 2015/16 passaram-se dezoito anos. Nesse período, a inflação e a deflação do preço de muitos produtos que envolvem os custos de produção e o próprio valor da saca de soja variaram significativamente. Dessa forma, os dezoito anos corridos de uma safra para a outra requerem um cálculo que considere a inflação e a deflação do que envolve os custos

\footnotetext{
12 Os preços da saca de soja podem sofrer variações no decorrer do ano e de um ano para outro, ou seja, é preciso considerar que a lucratividade que os produtores obtêm com o plantio da soja é relativa, e, às vezes, pode não acontecer. Em linhas gerais, para os produtores com lavouras de grande escala, como no estado de MT, os ganhos são maiores, pois mesmo que se ganhe pouco por saca produzida, quando a quantidade produzida é grande, o ganho real também acaba sendo alto. Ademais, a cotação do valor da saca de soja possui estreita relação com a Bolsa de Chicago (CBOT) e a Bolsa de São Paulo (Bovespa). O preço doméstico depende ainda de descontos, ou acréscimos, do prêmio de exportação e dos custos de movimentação do produto na área produtora para os portos. Assim, a influência do dólar nesse mercado é direta. Além disso, a boa produtividade do grão nem sempre significa lucro direto, pois, no caso da soja transgênica, podem surgir inúmeras pragas e/ou doenças capazes de fazer o produtor aumentar o custo com tratamentos e, com isso, o lucro diminuir ou desaparecer. Recentemente, o lucro dos produtores de soja tem sido satisfatório, pois o produto tem boa cotação.
} 
de produção, bem como o valor da saca de soja. Assim, atualizando o lucro de $\mathrm{R} \$ 167.000,00$ que, em hipótese, um agricultor obteria no estado de MT na safra $1997 / 98$, esse valor corresponde a $\mathrm{R} \$ 719.874,42^{13}$ no momento do levantamento dos dados de custo de produção da Tabela 2 (2015/16). Dessa maneira, na realidade, não se obteve um aumento de lucro quinze vezes maior da primeira para a segunda safra, mas sim um aumento real, considerando a inflação, de aproximadamente três vezes.

Nessa perspectiva, como se apontou, com base na cotação de preços da saca de soja da Aprosoja-MT, na colheita da safra 1997/98, a saca de soja não valia $\mathrm{R} \$ 11,93$, mas, na realidade, com a atualização desse valor, para comparar com a safra 2015/16, a saca de soja valia $\mathrm{R} \$ 51,93$. Paralelamente, o agricultor que vendeu seu produto no momento da colheita na safra 2015/16 conseguiu o preço de $\mathrm{R} \$ 73,75$, o que representa um aumento real de preço da saca de soja do ano de 1998 para 2016, de aproximadamente 30\%.

A análise dos custos de produção da soja no Brasil e a atualização dos preços de mercado, contabilizados todos os custos possíveis, dão margem para constatar que a lucratividade da sojicultura no estado de MT aumentou (VON DENTZ, 2018). Com isso, cabe analisar as transformações que ocorreram no espaço decorrentes desse aumento da lucratividade. Sendo assim, o próximo item versa sobre como o capital acumulado pelos agricultores de MT é usado e as transformações territoriais causadas pelo seu uso.

\section{O uso do capital acumulado no agronegócio da soja de Mato Grosso: repercussões no território}

A despeito de qual destino e de quais mudanças causadas nos locais para onde se dirige o capital acumulado, isto é, o lucro, formado no agronegócio do estado de MT, as constatações são decorrentes de informações coletadas em trabalhos de campo. No momento da realização dos trabalhos de campo, buscou-se

\footnotetext{
${ }^{13} \mathrm{O}$ cálculo de atualização dos valores monetários (inflacionados e/ou deflacionados) foi obtido por intermédio do Índice de Cálculos na Web (http://drcalc.net/Index.asp). Para esse caso, selecionou-se a linha que tem por base o IGP-M (FGV jun./1984 a set./2017), que, na prática, significa Índice Geral de Preços de Mercado estimados e contabilizados pela Fundação Getúlio Vargas, considerando o período de junho de 1984 a setembro de 2017 (período que compreende o tempo entre as safras 1997/98 - 2016/17).
} 
indagar os produtores de soja de Sorriso, visando à informação sobre os destinos que os agricultores dão para o lucro gerado no agronegócio de suas propriedades.

Com os resultados obtidos, elaborou-se um organograma que sintetiza as estratégias de investimentos dos agricultores de Sorriso. Na Figura 1, apresenta-se o referido organograma; com base nos resultados coletados em trabalhos de campo, prezou-se por dividir os investimentos em dois blocos: um ocorrido na área rural e outro na área urbana. Dessa forma, sem perder de vista que os resultados sistematizados são fruto do lucro obtido pelos agricultores na produção de soja, pode-se dizer que a relação estabelecida entre o agronegócio e a cidade, a partir dos investimentos oriundos do capital acumulado no agronegócio, gera um conjunto de características que permitem afirmar que se trata de uma relação de complementaridade, entre agronegócio e cidade, e não de disputa (Figura 1).

Figura 1 - Destinos do capital acumulado gerado pelo agronegócio do estado de MT

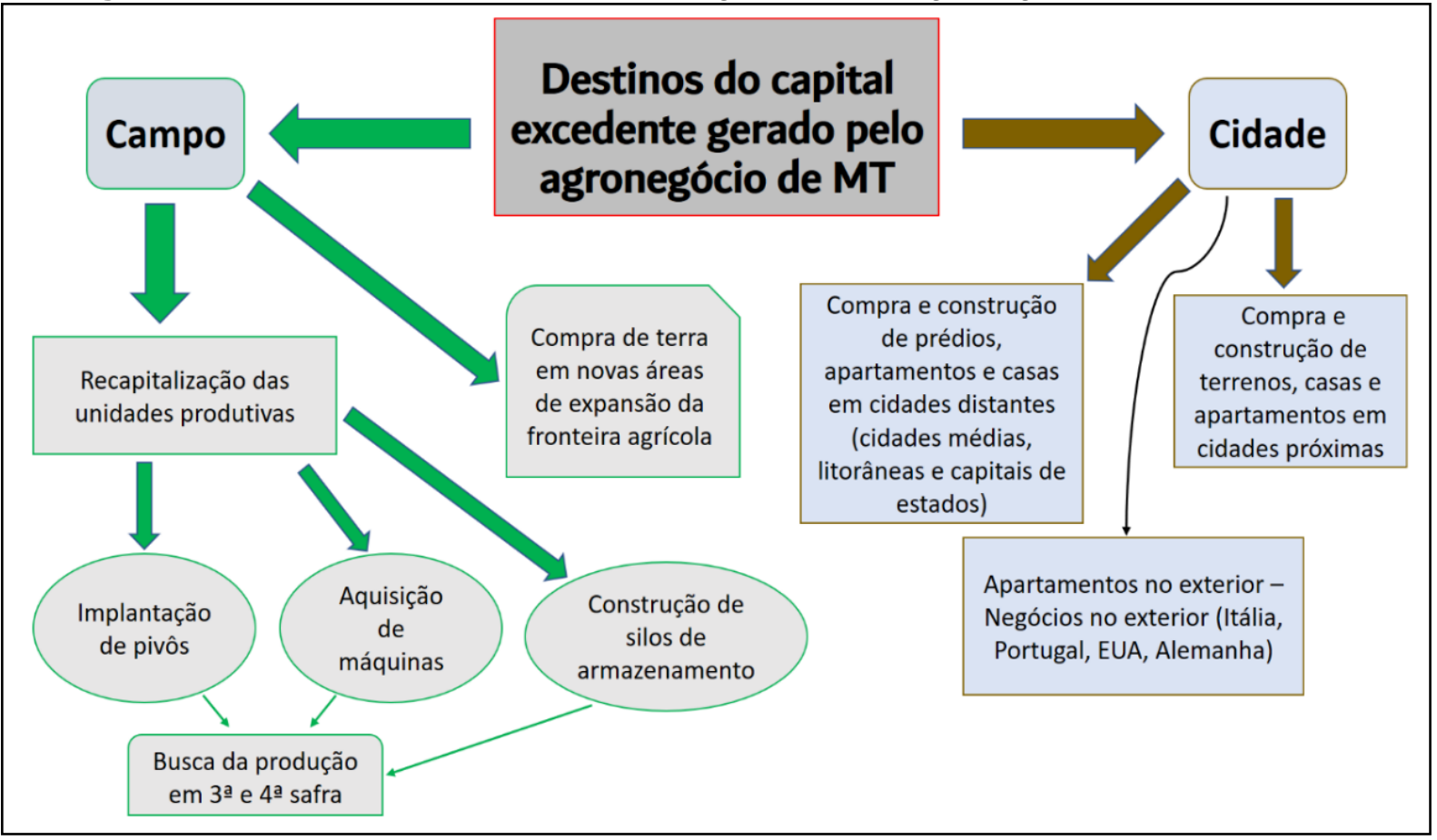


Fonte: Coleta de dados em trabalho de campo, out. 2016. Elaborado pelos autores.

É importante destacar que não foi possível levantar valores exatos sobre quanto $(R \$)$ os agricultores de Mato Grosso reservam, do total acumulado, para investir na perspectiva indicada na Figura 1. Por essa razão, os resultados da síntese apresentada na referida Figura são oriundos de uma interpretação retirada das informações coletadas nas entrevistas realizadas com os agricultores do município de Sorriso. Assim, no que diz respeito aos investimentos na área rural, no ramo do agronegócio, pode-se dizer que eles ocorrem na perspectiva de os agricultores forjarem uma recapitalização das unidades produtivas ${ }^{14}$. Isso ocorre visando aumentar a produtividade das culturas já produzidas (soja, milho e algodão) e abrir a possibilidade de fazer uma terceira e até mesmo a quarta safra no mesmo ano. A terceira safra seria para a produção de feijão, arroz ou trigo ${ }^{15}$. A quarta seria apenas para intensificar a cobertura orgânica do solo e a dinâmica de rotação de cultura, sendo feita majoritariamente por milheto, nabo ou sorgo, no intuito de fazer com que o solo seja preservado e tenha força produtiva suficiente para uma boa produção no ano seguinte (VON DENTZ, 2018).

A recapitalização das unidades produtivas (Figura 1) acontece especialmente com a implantação de pivôs de irrigação (viabilizando a possibilidade de mais de duas safras por ano); a aquisição de novas máquinas (que contenham toda a tecnologia necessária para plantio, pulverização e colheita dessas diferentes culturas); e a construção de silos de armazenamento de grãos (viabilizando o armazenamento da produção, sobretudo quando, no momento da colheita, o preço dos produtos não é bom o suficiente para cobrir os custos de produção). Com os recursos implantados na recapitalização das unidades produtivas, a ideia dos agricultores é garantir boa produtividade nas culturas de soja e milho ( $1^{\underline{a}}$ e $2^{\underline{a}}$ safras) e uma possível boa colheita na terceira safra. A garantia da boa produtividade se dá principalmente em virtude da implantação dos pivôs de irrigação, pois com eles elimina-se a margem de perda da produção por falta de chuva nos meses secos (abril a setembro).

14 Essa recapitalização ocorre num cenário agrícola no qual as propriedades rurais já estão equipadas com alta tecnologia para desempenhar as funções do agronegócio, sobretudo de soja, milho e algodão.

${ }^{15}$ No caso da cultura do trigo, existem pesquisas que estão apontando a possibilidade viável de cultivar trigo no Cerrado, o que até então não vinha ocorrendo, devido às condições climáticas e características do solo. 
Essa análise permite uma relação com o que Marx (2014) chamou de reprodução ampliada do capital. A funcionalidade do agronegócio no modo capitalista de produção impõe aos produtores que suas fazendas necessitam ampliar o lucro obtido. A recapitalização das unidades produtivas dá aos agricultores a possibilidade de manter ou aumentar sua mais valia, isto é, sua margem de lucro. Aumentar a mais valia, tal como Marx (2014) aponta, é tão necessário que, se os agricultores não o fizerem, poderão ser excluídos da atividade, haja vista as necessidades impostas pelo capitalismo de continuar investindo visando ao lucro. Em outras palavras, é preciso constantemente aumentar a produção para continuar acrescendo ou mantendo o lucro no sistema capitalista.

Ademais, caso esse aumento de produção não aconteça, no viés aqui apresentado, os agricultores abrem caminho para o endividamento agrícola ${ }^{16}$ e, em último caso, para o abandono das atividades ligadas ao agronegócio. Portanto, há, no gerenciamento das atividades do agronegócio pelos agricultores de MT, a necessidade imposta pelo capitalismo de aumentar seus indicadores de produção para continuar com a viabilidade econômica no próprio agronegócio ou fora dele.

Além da recapitalização das unidades produtivas, como sistematizado no lado esquerdo da Figura 1, outra forma utilizada pelos agricultores para o emprego do capital acumulado extraído do agronegócio é o investimento nas cidades (lado direito da Figura 1). Este, por sua vez, conquanto também seja realizado em vista da acumulação de capital, segue uma lógica diferente, no sentido de que, da maneira como foram coletadas as informações nos trabalhos de campo, parece que investir na cidade serve como uma válvula de escape para os agricultores, não sendo este o centro das atenções para aplicação do capital acumulado extraído do agronegócio. O que realmente movimenta o poder econômico do agronegócio são os investimentos realizados no próprio agronegócio, como analisado anteriormente. $\mathrm{E}$ isso, todavia, não diminui a importância dos investimentos que os agricultores realizam nas cidades.

Nas cidades, estrategicamente, os agricultores investem visando "não perder dinheiro", uma vez que a valorização dos imóveis urbanos, sobretudo entre 2010 e 2016, tem atraído investimentos dos agricultores. De modo geral, o crescimento das cidades tem acontecido em paralelo com a especulação imobiliária, o que acaba

16 O endividamento agrícola, em muitas circunstâncias, não é sinônimo de fracasso dos agricultores. Pelo contrário, muitos agricultores fazem a gestão de suas dívidas para poder continuar na atividade. 
contribuindo para a valorização dos imóveis urbanos. Na Figura 2, pode-se observar um edifício situado na cidade de Lucas do Rio Verde/MT, cujos apartamentos foram vendidos com valor contado em sacas de soja. De acordo com informações coletadas em trabalhos de campo, um apartamento do prédio que aparece na Figura 2 chegou a ser vendido por 16 mil sacas de soja (cerca de 1 milhão de reais).

Figura 2 - Edifício de alto padrão com valor de venda em sacas de soja

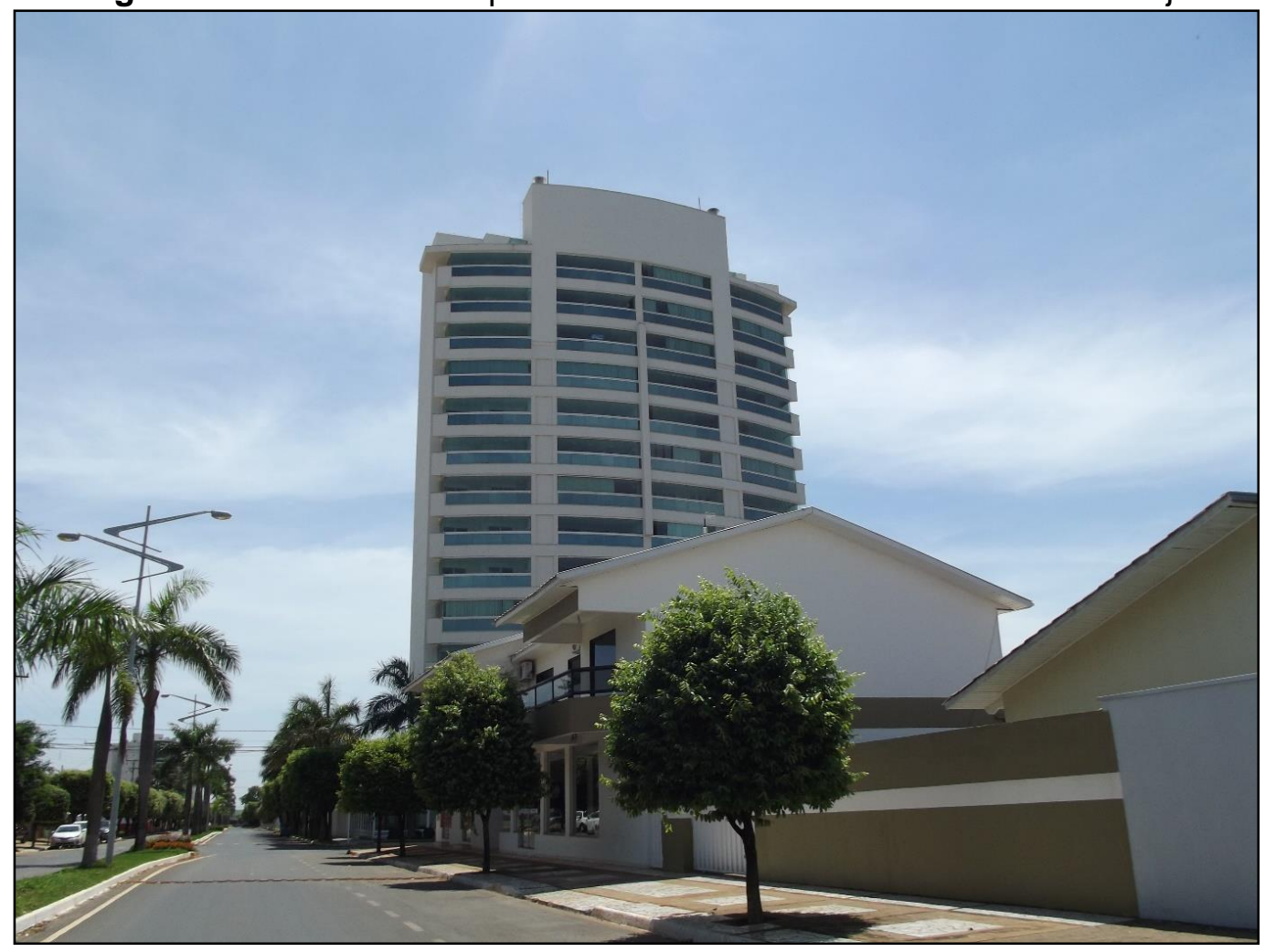

Fonte: Foto dos autores. Trabalho de campo, outubro de 2016 (Lucas do Rio Verde/MT).

Como pode ser visto na Figura 2, trata-se de um edifício de alto padrão, sobre o qual, principalmente, agricultores da região de Lucas do Rio Verde-MT realizam seus investimentos para compra dos apartamentos. Assim, esse fato não apenas mostra como a relação entre o agronegócio e a cidade se dá de maneira direta e complementar, como também aponta para uma das três formas nas quais o capital gerado no agronegócio é aplicado na cidade (Figura 1), isto é, a investida de capital do agronegócio em cidades próximas às regiões produtoras do agronegócio. Em cidades como Lucas do Rio Verde e Sorriso, de acordo com o que foi constatado, é comum encontrar esse tipo de investimento.

Outro ponto que pode ser destacado são os investimentos que, por vezes, os agricultores optam por realizar em cidades distantes (Figura 1). Esses investimentos são realizados estrategicamente pelos agricultores, visando à valorização do seu capital gerado no agronegócio, mas são investimentos que possuem um motivo 
extra adicionado. Um exemplo que pode ser citado é que, em muitos casos, os agricultores que trabalham com o agronegócio em MT imigraram do Sul do Brasil (Sudoeste, Norte e Oeste do PR, Oeste catarinense e Norte e Noroeste do RS) nas décadas de 1980 e 1990. Atualmente, esses agricultores têm filhos em idade de realização dos seus estudos universitários. Como há um "consenso" nos agricultores de MT de que as universidades do Sul do Brasil são melhores para o estudo de seus filhos, muitas vezes os agricultores os enviam para estudar no Sul do país. Nessa oportunidade, acabam investindo na compra de apartamentos em cidades do Sul do Brasil, para seus filhos morarem enquanto fazem a graduação, mas, ao mesmo tempo, estrategicamente, visando à valorização do capital investido ${ }^{17}$.

Além disso, há agricultores que aproveitam a justificativa de ter o filho estudando no Sul do Brasil para adquirir grande número de imóveis, e, muitas vezes, até mesmo edifícios inteiros. Esse dado ajuda a explicar, sem saber dizer em que medida, devido à dificuldade de dados concretos para essa questão, o acelerado crescimento urbano, ou seja, a rápida verticalização urbana em cidades nas quais há boa oferta de ensino universitário ${ }^{18}$, como, por exemplo, Chapecó/SC, Pato Branco/PR, Passo Fundo/RS. O maior vazio existente na afirmação desses investimentos é o fato de não ser possível sua confirmação por meio de dados. Os agricultores não "abrem o jogo" no sentido de apontar diretamente quais as quantidades e quais as cidades do Sul do Brasil que recebem esses investimentos. No entanto, ainda que de modo incipiente, essa informação pode contribuir para os estudos a respeito do crescimento das cidades médias no Sul do Brasil.

Da mesma forma, os investimentos, além de serem sempre feitos estrategicamente tendo em vista a valorização dos valores investidos, são realizados para finalidades de lazer e ocupação esporádica. Nos trabalhos de campo, foram citados investimentos em apartamentos localizados no litoral de SC e em cidades localizadas no litoral do Nordeste brasileiro, estritamente usados para o lazer dos agricultores. Muitas vezes, os agricultores optam por investir em capitais, como Curitiba, Porto Alegre, Goiânia e Cuiabá, por serem capitais com bons recursos

\footnotetext{
17 Nos trabalhos de campo, houve afirmação de que as três capitais dos estados da região Sul recebem investimentos do agronegócio de MT em forma de empreendimentos imobiliários. Ademais, cidades médias que possuem vasta oferta de cursos universitários entram nesse quadrante, como, por exemplo: Chapecó, Cascavel, Passo Fundo.

18 Não se trata apenas da oferta de ensino universitário que leva os agricultores de MT a investirem nessas cidades, mas um conjunto de questões, como a infraestrutura aeroportuária, serviços médicos, redes bancárias, dentre outras.
} 
médicos (clínicas, hospitais e especialistas da medicina) e com grande disponibilidade de voos nos aeroportos. Assim, em caso de urgência para tratamentos de saúde, em caso de realização de viagens de negócio ou turismo, o uso de um aeroporto maior torna-se necessário. Os agricultores de MT optam, estrategicamente, pelo investimento em capitais de estados que oferecem tais recursos ${ }^{19}$.

O último ponto a ser analisado na Figura 1, que não deixou de chamar a atenção, foram os investimentos em cidades localizadas fora do Brasil. Alguns agricultores escolhem comprar imóveis em países, como Estados Unidos (Miami, Orlando, Atlanta), Itália (Milão), Alemanha (Berlim, Munich) e Portugal (Lisboa, Porto $)^{20}$. Os agricultores optam pelos investimentos fora do país porque têm o hábito de visitar esses países, ou porque possuem amigos e/ou parentes lá, ou ainda porque estudaram nesses países, nessas cidades, dentre outros motivos. No entanto, esses investimentos fora do Brasil são mais raros, se comparado aos investimentos realizados nas cidades próximas das regiões produtoras do agronegócio.

Embora toda essa discussão sobre os investimentos estratégicos feitos com base no lucro extraído do agronegócio do estado de MT seja de grande relevância, quando se trata de entrelaçar esses investimentos com a cidade, vale mencionar Corrêa (1999), o qual afirma que são os proprietários dos meios de produção, os proprietários fundiários, os promotores imobiliários, o Estado e as camadas sociais marginalizadas que produzem o espaço urbano. Nesse contexto, o dinheiro investido nas cidades, advindo do agronegócio, faz parte de apenas uma parcela do complexo de investimentos realizados na compra e construção de imóveis urbanos.

Corrêa (1999) ressalta que, no tocante à produção do espaço urbano atrelado ao agronegócio, isto é, aos proprietários de terras, diz respeito a uma estratégia dos agricultores (do agronegócio) de obter renda ainda maior do que já foi extraído da produção agrícola, especialmente quando se trata de usar o dinheiro do agronegócio

\footnotetext{
${ }^{19}$ Vale salientar que, quando essas informações foram fornecidas, os agricultores foram indagados se também realizam algum tipo de investimentos na cidade de São Paulo, haja vista que esta possui a maior infraestrutura nesse sentido. Os agricultores responderam que não, pois é um centro muito grande, com uma dinâmica urbana que incomoda, que não interessa. Outro ponto que merece ser destacado é que a coleta dessas informações se deu em outubro de 2016, época em que o preço dos grãos, sobretudo soja e milho, encontravam-se numa situação confortável, o que, na safra 2015/16, garantiu aos agricultores maior extração de lucro das lavouras. Estima-se, com isso, que os negócios entrelaçados com as cidades foram ampliados nessa oportunidade.

20 Os investimentos em cidades do exterior, pelo que foi possível notar nas entrevistas, são ações de agricultores que plantam áreas acima de 20 mil ha e, portanto, extraem maior lucro das lavouras.
} 
para uso urbano comercial, residencial e até mesmo para status social. Ademais, muitos agricultores, especialmente os mais poderosos, usam dos recursos do Estado para valorizar suas propriedades, tanto na área rural quanto na área urbana, principalmente no quesito infraestrutura, especialmente com asfaltamentos, instalação de redes de eletricidade, linhas telefônicas, dentre outros.

\section{Considerações Finais}

Constatou-se, no artigo, a importância da produção da soja no estado de MT, especialmente no município de Sorriso, tanto a partir da evolução de seu volume produzido, quanto da sua área plantada e da produtividade. Trata-se do principal produto cultivado na agropecuária do estado. Nesse sentido, entre as razões que fazem da soja o produto agrícola mais cultivado no estado de MT está sua lucratividade (como apontado nos dados sobre o município de Sorriso). Conforme demonstrado, os produtores do estado de MT plantam áreas de terra maiores (em média 1.500 hectares) do que em outros estados, o que permite aos produtores lucro maior, depois de subtraído os custos de produção. Esses lucros permitem aos agricultores a realização de investimentos no próprio agronegócio, mas também nas cidades.

Assim sendo, é possível constatar a acumulação de capital para os produtores de soja de MT, especialmente para aqueles que plantam áreas ainda maiores do que à média de área supracitada. A acumulação do capital baseada no agronegócio da soja gera uma série de outros investimentos que reorganiza as configurações territoriais de muitos lugares, além daqueles situados no entorno das áreas produtivas. Nessa direção, o capital acumulado no agronegócio da soja é investido, principalmente, em duas frentes: uma no campo e outra na cidade. No campo, ou seja, no próprio agronegócio, o capital acumulado no agronegócio da soja é aplicado em três principais tipos de investimentos: implementação de pivôs de irrigação, aquisição de novas máquinas agrícolas e construção de silos de armazenamento de grãos. Nas cidades, o capital acumulado no agronegócio da soja é utilizado na compra e/ou construção de prédios, apartamentos e casas de alto padrão nas cidades próximas das áreas produtivas (por exemplo: Lucas do Rio Verde e Sorriso); nas cidades distantes das áreas produtivas (por exemplo: Chapecó/SC, Pato Branco/PR, Cuiabá/MT, Balneário Camboriú/SC); e em cidades do exterior (por exemplo: Porto, Lisboa, Milão, Miami). 
Por outro lado, embora os investimentos do capital acumulado no agronegócio sejam recorrentes de ocorrerem nas cidades, vale salientar que os investimentos mais significativos que os produtores de soja realizam se dão no próprio agronegócio. Desse modo, trata-se de movimentações de capitais que almejam, a todo momento, o progresso das atividades produtivas, o que inevitavelmente causa transformações significativas no território. Assim, é o capital produzido pelo agronegócio da soja um grande responsável pelos movimentos geoeconômicos das regiões produtivas do agronegócio de MT.

Portanto, este artigo desvendou não apenas a capacidade de acumulação de capital do agronegócio da soja no município de Sorriso (estado de MT), mas também apontou para as principais transformações territoriais decorrentes da maneira como esse capital acumulado é investido. Além disso, os resultados aqui obtidos servem, em alguma medida, para quebrar o paradigma existente de que o agronegócio conduz mudanças apenas no entorno de suas áreas produtivas. Como foi possível verificar, sobretudo quanto ao uso de o capital acumulado ocorrer nas cidades, muitas vezes é usado em cidades distantes das áreas produtivas e até mesmo em cidades de outros países.

\section{Referências Bibliográficas}

BERNARDES, Júlia Adão. Novas fronteiras do capital no Cerrado: dinâmica e contradições da expansão do agronegócio na região Centro-Oeste, Brasil. Scripta Nova, v. xix, n. 507, p. 1-28, Barcelona: Universidad de Barcelona, 2015.

BIELSCHOWSKY, R. Estratégia de Desenvolvimento e as três frentes de expansão no Brasil: um desenho conceitual. In: Texto para Discussão. n. 1828, Brasília: IPEA. abr. 2013.

CONAB. Anuário da soja. 2016. Disponível em: https://www.conab.gov.br/. Acesso em: 20 nov. 2019.

CORRÊA. Roberto Lobato. O espaço urbano. 4. ed. São Paulo: Ática, 1999.

DINIZ, Bernardo Palhares Campolina. O grande Cerrado do Brasil Central: geopolítica e economia. 231f. Tese (Doutorado em Geografia) - Universidade de São Paulo. Programa de Pós-graduação em Geografia Humana, da Faculdade de Filosofia, Letras e Ciências Humanas, São Paulo, 2006. 
ESPÍNDOLA, Carlos. J. Ciclo de crescimento da economia brasileira e desempenho do agronegócio catarinense. Geografia (Londrina), v. 25, p. 91-109, 2016.

$\mathrm{FICl}$, Ricardo Petrillo. As ferrovias brasileiras e a expansão recente para o CentroOeste. 339f. Dissertação (Mestrado em Geografia) - Universidade de São Paulo. Programa de Pós-graduação em Geografia Humana do Departamento de Geografia da Faculdade Filosofia, Letras e Ciências Humanas, São Paulo, 2007.

FREDERICO, Samuel. O Novo Tempo do Cerrado: Expansão dos Fronts Agrícolas e Controle do Sistema de Armazenamento de Grãos. São Paulo: AnnaBlume, 2008.

GUIMARÃES, E. N.; LEME, H. J. C. Caracterização histórica e configuração espacial da estrutura produtiva do Centro-Oeste. In: HOGAN, D. J. et al. (org.). Migração e ambiente no Centro-Oeste. Campinas: UNICAMP, 2002. 324p.

IBGE. Estimativas da agropecuária. 2016.

IBGE. Pesquisa Agrícola Municipal. Rio de Janeiro, 2016. Disponível em: https://sidra.ibge.gov.br/. Acesso em: 30 nov. 2019.

IMEA. Instituto Mato-grossense de Economia Agrícola. Boletim anual. 2016.

MARX, Karl. O capital: crítica da economia política: Livro I: o processo de produção do capital. São Paulo: Boitempo, 2014. 894 p.

REZENDE, Gervásio Castro de. Ocupação agrícola e estrutura agrária no Cerrado: o papel do preço da terra, recursos naturais e tecnologia. Rio de Janeiro: IPEA, Texto para Discussão, n. 913, out. 2002, 23p.

VON DENTZ, Eduardo. Dinâmica espacial da acumulação de capital do agronegócio: o caso do Mato Grosso. 2018. 201f. Dissertação (Mestrado em Geografia) - Universidade Estadual do Oeste do Paraná, Francisco Beltrão, PR, 2018.

\section{NOTAS DE AUTOR}

\section{CONTRIBUIÇÃO DE AUTORIA}

Eduardo von Dentz - Concepção. Coleta de dados, Análise de dados, Elaboração do manuscrito, revisão e aprovação da versão final do trabalho

Fernando Rodrigo Farias - Concepção e elaboração do manuscrito; Participação ativa da discussão dos resultados.

\section{FINANCIAMENTO}

Coordenação de Aperfeiçoamento de Pessoa de Nível Superior (CAPES).

\section{CONSENTIMENTO DE USO DE IMAGEM}

Não se aplica.

\section{APROVAÇÃO DE COMITÊ DE ÉTICA EM PESQUISA \\ Não se aplica.}


LICENÇA DE USO

Este artigo está licenciado sob a Licença Creative Commons CC-BY. Com essa licença você pode compartilhar, adaptar, criar para qualquer fim, desde que atribua a autoria da obra.

\section{HISTÓRICO}

Recebido em: 29-01-2021

Aprovado em: 03-07-2021 